\title{
The Reality of Using E-learning Strategies to Improving the Learning of Mathematics for Undergraduate Students
}

\author{
Dr. Yasir Ahmed Al Raiss Ahmed ${ }^{1,2}$ \\ ${ }^{1}$ Assistant Professor, Department of Educational Sciences, College of Education in Wadi Al-Dawasir, Prince Sattam \\ Bin Abdul-Aziz University, Saudi Arabia \\ ${ }^{2}$ Assistant Professor, Department of Curricula and Methods of Teaching, College of Education, University of \\ Khartoum, Sudan \\ Correspondence: Dr. Yasir Ahmed Al Raiss Ahmed Department of Educational Sciences, College of Education in \\ Wadi Al-Dawasir, Prince Sattam Bin Abdul-Aziz University, Saudi Arabia.
}

Received: November 22, 2020

Accepted: December 23, 2020 Online Published: December 24, 2020

doi:10.5430/ijhe.v10n3p75

URL: https://doi.org/10.5430/ijhe.v10n3p75

\begin{abstract}
This research aims to know the reality of using e-learning strategy in improving the learning of mathematics in university education, and to know the moral differences between the variables, the researcher used the descriptive and analytical method with the questionnaire tool consisting of (30) paragraphs distributed in the fields of education, learning and evaluation, addressed to a random sample of (110) students and the Mathematics teaching staff of (34) members of Prince Sattam bin Abd Al-Aziz University in Wadi Al-Dawasir at tow Colleges (Arts, Sciences and Engineering) for the first semester of the academic year 2021.

After collecting and analyzing data statistically, the researcher came up with the following findings: The most important ones are: the existence of good efficiency in using e-learning strategies in teaching Mathematics, learning and evaluation process, especially in the focus of education, the presence of obstacles in the way of the use of e-learning strategies in learning the university student, especially weak internet, and the absence of statistically significant differences in the efficiency of using strategies of e-learning in learning Mathematics for gender, and for the cumulative academic rate, there is an urgent need for training faculty members and students to improve the use of e-learning strategies in teaching and learning Mathematics, especially when it comes to developing.

The research came up with a set of recommendations the most important of which is increasing community awareness to calling for: action to spread the culture of using e-learning in teaching in universities, addressing the obstacles facing the use of e-learning strategies, draw attention to training students and members of Mathematics teaching staff on what is new in the field of educational technologies.
\end{abstract}

Keywords: teaching strategies, e-learning, reality of using, improvement, mathematics learning

\section{Introduction}

Mathematics is a rigid subject and its teaching requires the involvement of many senses to contribute to its simplification and understanding, hold great hopes for the contribution of mathematics to solving many of the problems and challenges facing humanity, so the teaching and learning of mathematics receives great attention, and the acceleration of cognitive and technological development has contributed to providing the best interactive learning environment that suits the needs of learners, and helps them develop their abilities to deal with variables This era. Al-Halafawi (2011) affirms the rapid growth of Internet technologies demonstrated the necessary need to introduce modern educational systems to improve education by integrating technology into the teaching and learning process, and Karawani (2012) adds that traditional methods have been greatly affected by technical development, which led to an increase in the efficiency of higher education. In all his majors, including mathematical sciences.

There is no doubt that the teaching strategies have the greatest impact on the learner's motivation towards learning, the amount of knowledge, skills and values obtained from education and the duration of their impact in the learner's mind and benefiting from them. Also, the adopted evaluation strategies constitute great success in diagnosing and treating the reasons for the success and failure of the entire learning process. Alvarez \& Others (2015) believes that the use of the Internet, have imposed a new paradigm in the field of education, the most important of which is the abandonment of traditional methods and their replacement with e-learning methods. Hubackova (2015) affirmed that the progress of 
e-learning is linked to technological progress has helped the emergence of various educational styles, that transcends space, time, material capabilities, and differences in the capabilities and needs of individuals. Therefore, e-learning and e-Instruction is a necessary requirement at the present time.

\section{Research Problem}

Makgato (2014) referred to in the last decade, South African universities have adopted various e-learning platforms and are thus striving to favorably compete with other universities across the globe in the higher education domain in interest in e-learning and activating its use, to simplify some difficult courses, and teach students how to obtain information, and Al-Hamili (2005), explained that the use of computers has become an integral part and an important criterion for measuring the progress of contemporary societies.

The most important pillars of the general objectives of the education policy in the Kingdom is the introduction of the latest technology reached in the world, and Al-Harbi (2007) indicated to introduce computers in the schools of the Kingdom of Saudi Arabia in the year $1405 \mathrm{AH}$ as part of the developed secondary education program, then the Ministry of Education adopted in the Sixth National Conference The tenth of the year 1422 AH, for the computer, and for the e-learning project, in implementation of the National Plan for Information Technology. Alvarez, D. and others (2015) note that the use of technology in teaching mathematics increases the chances of learning and understanding it, and also contributes to increasing learner motivation.

The outbreak of the (Corona 19) pandemic was a motivation for most countries to use e-learning strategies at all educational levels in compliance with health protocols, and the mathematics is a rigid subject, and one of the main reasons for students 'aversion to studying it is to present it in an abstract way. Padayachee (2017), have also acknowledged the efforts of HEIs in training academics/instructors on the intricacies of e-leaning towards effective and efficient use for learning. Therefore, the research problem becomes evident to know the reality of using e-learning strategies in the teaching and evaluation process to improve mathematics learning for undergraduate students from the students' own point of view.

\section{Importance of the Research}

- Helping upgrade methods (teaching, learning, and evaluation) in mathematics at the university level.

- Identify barriers to using e-learning strategies to improve undergraduate mathematics learning

- Determining the moral differences between the effectiveness of using e-learning strategies and variables.

- Determining the need for training to take advantage of the characteristics of e-learning in teaching, learning and evaluating mathematics.

In general, research can help support and encourage faculty members and students to use e-learning strategies in teaching various subjects at the university level

\section{Research Objectives}

- Identify the reality of using the e-learning strategy to achieve improvement in the process of learning mathematics through the axes of education and evaluation from the students' point of view.

- Identify the obstacles facing the use of the e-learning strategy in the process of teaching, learning and evaluating mathematics at the university level.

- To know the extent of the existence of statistically significant differences between the overall averages of students' responses about the use of e-learning strategies in improving the learning of mathematics due to the GPA variable (less than 3,3 or more)?

- Identify the extent of the existence of statistically significant differences between the overall averages of students' responses about the use of e-learning strategies in improving the learning of mathematics due to the gender variable (male, female)?

- Identify the extent to which students and faculty members need training to take advantage of the features provided by e-learning in improving the learning of mathematics.

\section{Research Variables}

The Independent Variable: using e-learning strategy in improving the learning of mathematics

The Dependent Variable: the GPA variable, the rate variable gender.

The Fixed Variable: teaching, evaluation 


\section{Research Questions}

1- What is the role of using the e-learning strategy in achieving improvement learning of mathematics at the undergraduate level from the students' point of view?

2- What are the obstacles facing the use of the e-learning strategy in the process of teaching, learning and evaluating mathematics at the university level?

3- Are there statistically significant differences between the overall averages of students 'responses to the use of the e-learning strategy to improve learning of mathematics due to the GPA variable (less than 3, 3 or more)?

4- Are there statistically significant differences between the overall averages of students 'responses to the use of the e-learning strategy to improve learning of mathematics due to the rate variable gender (male, female)?

5- What is the need for training to take advantage of the characteristics provided by the use of e-learning strategies to improve the teaching, learning and evaluation of mathematics?

\section{Research Terms}

Effectiveness: improvement or effectiveness defined by Harvey (2004), as an indication of the extent to which the activity and the function or goal to be achieved is achieved.

The idiomatic definition is that it is an expression of the ability of using the e-learning strategy to achieve improvement in teaching, learning and evaluation of mathematics at the university level.

Teaching Strategy: Protheroe \& Clarke (2008) defines it as a complex set of processes in which teacher and student activities interact, aimed at enhancing and improving learner performance.

The idiomatic definition is a set of activities, procedures, measures and steps that a member of the mathematics faculty at the university undertakes in order to facilitate the achievement of specific objectives for the lesson.

E-learning: Epignoss (2014), defines it as an educational tool or strategy that relies in essence on the computer via the Internet, which enables the learner and helps him to learn anywhere and at any time, and bridges the geographical gap.

The idiomatic definition is that it is a strategy in which a member of the mathematics faculty uses modern communication technology to facilitate the delivery of information to the learner, whether inside or outside the classroom.

\section{Research Limits}

- Time limits: The research is applied during the first semester of the academic year 2021 AD.

- Spatial limits: This research is limited to the College of Sciences and Arts and the College of Engineering at Prince Sattam Bin Abdulaziz University in Wadi Al-Dawasir.

- Objective limits: This research is limited to the extent of using e-learning strategies in improving the learning of mathematics at the university level from the students' point of view.

- Human Limits: This research is limited to a random sample of students, and mathematics faculty members at Prince Sattam bin Abdul-Aziz University in Wadi Al-Dawasir.

\section{The Theoretical Framework and Literature Review}

\subsection{Theoretical Literature}

\subsubsection{First: the Concept of E-learning and Its Uses}

E-learning is seen as a teaching method to transfer the content to the learner by multiple electronic means. Al-Arifi (2003), confirmed that providing educational content by advanced programs stored in the computer or over a network Internet. It is also viewed as an integrated system that has its own inputs, processes and outputs.

E-learning is a form of modern education that combines active learning and teaching techniques through the use of electronic content provided by the teacher in a way that allows the learner to access it easily, at any time and at a speed that suits his conditions and abilities (Zaitoun, 2005).

Al-Mubarak (2005), indicates that e-learning is employed in teaching in several ways as an auxiliary model, as various platforms learning, as a mixed model, and as a pure model. Among his methods of educational games and simulations (Comerchero, 2005).

In order to facilitate the process of interaction between the student and the teacher, e-learning is managed with an integrated computer system, Abdel Aziz (2008) indicates that e-learning programs can be evaluated through electronic 
evaluation methods. Azmi (2006) adds, self-assessment, projects, electronic portfolios. Self-evaluation and interviews can also be used (Amanda, A., Andrea, M. \& Mike, M, 2006).

\subsubsection{Pros and Cons of Using E-learning}

The use of e-learning has many advantages, including that it is flexible education, in which content is presented through modern electronic media, generates an interactive learning environment, it does not eliminate the role of the teacher but changes from it, DLal, Z., Al-Jundi, A. (2005), explained that education Electronic enhances the teacher's role as a supervisor, mentor, and organizer to manage the educational process. As for its benefits for the student, it is easy to understand and assimilate information, obtaining information in an updated at any time and any place.

Al-Musharraf (2004), points out the disadvantages and defects of using e-learning, including the weakening of the educational and educational role of the teacher, the greater focus on cognitive aspects, the development of introversion of learners, the focus on the sense of sight and hearing, the difficulty of practicing non-educational activities, and it reduces the level of creativity and innovation in answers in exams. Sackstein, et al. (2019), finds that some faculty are promising the use of LMS as overtime, and thus have no motivation to use an e-learning platform to teach their students

\subsubsection{Importance and Objectives of Using E-learning}

Mansour (2015) emphasizes its importance in reducing time and effort to achieve educational goals with high efficiency, making learning an interesting and enjoyable process for the learner, and contributing to solving the problem of knowledge explosion and the increasing demand in education, and enabling continuous training While working, satisfying the needs and characteristics of the learner and reducing the cost of education, expansion of perceptions among the teacher and the student, the speed of changing programs and curricula on the Internet, and with the lowest costs, overcoming geographical barriers, improving teachers 'and learners' attitudes towards teaching and learning. The expected benefits of using electronic strategies are influenced to some extent by gender, age, experience, and willingness of use, as pointed out by Viswanath et al. (2003).

Al-Todri (2001) affirms the overall goals of e-learning to organize the work of educational institutions and their departments, creating an interactive educational structure, providing the opportunity for students to interact through the Internet, and supporting the relationship and interaction between students and teachers, to provide education that is appropriate for different age groups and taking into account individual differences.

\subsubsection{Obstacles to Using E-learning}

The novelty of the experience obstacles that prevent e-learning from achieving its goals fully, Al- Dayel, and Salama (2004) add that lack of response Learners and their interaction with this new pattern, lack of trained human cadres to prepare appropriate courses for e-learning, lack of adequate awareness of community members with this type of education. Oyedemi (2012), also averred that the unavailability of Internet access. Al-Musa and Al-Mubarak (2005), add continuous updating to keep pace with developments in curricula, lack of incentives for the educational environment, loss of the human factor in education, the possibility of penetrating e-learning sites, lack of recognition of some Countries with certificates obtained by e-learning graduates, as well as Rubaai, and Hashim (2019) pointed that systemic challenges and limited skills occasioned by a lack of technical support, prevents the effective usage of e-learning in various HEIs.

\subsubsection{Mathematics and Its Learning thereof}

Aqeelan (2002), stated that mathematics is "an abstract science of the creation and creativity of the human mind and is concerned with, among other things, the sequence of ideas, methods, and patterns of thinking. It can be viewed as a way of thinking or a language that uses specific expressions and symbols with precision, or it is an organized knowledge in a structure or as an art." He is beautiful in symmetry and is concerned with studying patterns. Salama (2007), explained that mathematics is the most important pillar of any scientific progress, and mathematics is the building block in space, astronomy and electronic devices research. The modern vision of the twenty-first century of mathematics came to emphasize the urgent necessity to help learners to see mathematics as an exciting and useful topic, and to encourage teachers to use modern technologies to bring mathematical concepts closer to the minds of learners.

Because mathematics is an abstract subject, the importance of using educational techniques in teaching mathematics comes to stimulate students 'interest and satisfy their needs towards learning, to diversify teaching methods, and to increase learners' motivation to learn, pay attention and participate. Instead of assessing the level of knowledge, encourage divergent groups rather than local ones. Fathallah (2004), indicated that the use of e-learning in learning mathematics is one of the recent trends that many studies have recommended for their feasibility. 


\subsection{Literature Review}

The researcher reviews a number of studies related to the use of e-learning in the field of mathematics education, such as the study of Al-Maghribi (2000), aimed at finding out the effect of using programmed education as a method for teaching mathematics on student achievement. The researcher used the experimental method and the programmed booklet as a tool to present the educational program. The study found significant differences Statistical achievement of male and female students between the two groups in favor of the experimental group, there are no statistically significant differences in achievement between the sexes for the two groups, and the study of Al-Zahrani (2005), aimed to identify the reality of using computers and the Internet in teaching mathematics at the secondary stage, and the study reached the most important results: Computers as an educational tool were very low. Teachers 'tendencies in using the Internet in teaching mathematics are positive and high. The study of Al-Hadi (2005), aimed to find out the effect of using computers in teaching mathematical skills on first-grade students' achievement in the Abu Dhabi educational region in the United Arab Emirates. , Concluded that there are statistically significant differences in achievement in favor of the male experimental group In the development of mathematical skills that attribute sex to the benefit of female experimentalism, the study of Al-Tamimi (2007), aimed to show the extent and importance of the availability of standards related to mathematics teaching from the point of view of mathematics teachers in three countries of Saudi Arabia, Jordan and Malaysia, the study reached results, the most important of which are: among mathematics teachers in the countries The three are aware of the importance of mathematics standards and the preference for these standards among mathematics teachers in Malaysia.

The reality of the infrastructure tends in favor of Saudi Arabia in terms of equipment and in favor of Jordan in terms of locally produced software by students, ready-made educational software for Malaysia, and the study of Al-Harbi (2007), aimed to define The demands of using e-learning that are required in (mathematics curriculum, mathematics teacher, educational environment) in the secondary stage, the study reached conclusions, the most important of which are all the demands of the electronic curriculum and the educational environment contained in the study tool is considered necessary and necessary, the absence of statistically significant differences at the level of $(005)$ between the average responses of specialists and practitioners in their determination of e-learning demands according to a variable (specialization, years of experience), the study of Abdel-Hafiz (2020), it aimed to measure the role of using e-learning strategies in achieving improvement in the process of teaching mathematics from the point of view of faculty and students. The descriptive analytical approach was used, and it showed that the degree of effectiveness of e-learning strategies in improving mathematics learning in general is closer to the level of good, the study of Abuhmaid (2020), aimed to find out students' perceptions of the impact of the online learning environment on the project-based teaching method, using the experimental approach, the results show that students in the classroom have stronger views of project-based learning than online learning students.

In terms of results, most of the previous studies that were presented agreed on the superiority of programmed education versus the previous method in the aspect of academic achievement, the existence of an effective effect of the computer on academic achievement, the development of positive trends for learners towards education, and it varied in the presence of statistically significant differences for the variable of gender and specialization and the academic rate.

It is noted that this study agreed with the study of Al-Zahrani, the study of Al-Harbi, and the study of Al-Tamimi in that it adopted the descriptive approach and the use of the questionnaire as a tool for collecting data. The current studies were distinguished from the previous studies in that they aimed to know the reality of using e-learning strategies for teaching and evaluation processes to improve mathematics learning for undergraduate students from student's own point of view.

\section{Research Methodology and Procedures}

\subsection{Research Methodology}

The researcher used the descriptive and analytical method with the questionnaire tool because it is the most appropriate approach to know the reality of using e-learning in improving the learning of mathematics at the university level, from the students' own viewpoint.

\subsection{Research Tools}

The questionnaire: Based on monitoring and tracking previous studies, and interviewing a number of mathematics faculty members, a questionnaire was formulated in its initial form directed to students and members of the mathematics faculty to know the reality of using e-learning strategies to improve the teaching, learning and evaluation of mathematics. 
Validity of the questionnaire: The questionnaire was given to a number of members of the teaching staff of mathematics and methods of teaching mathematics, psychology and education to demonstrate its validity in terms of clarity of the paragraphs and the extent of their belonging to the field that they measure, and to demonstrate the validity of the paragraph or amend or delete it.

Student questionnaire consisted of two parts, the first included information about the respondent according to the research variables, and the second included (30) paragraphs of the questionnaire, distributed (10) items for each of the teaching, learning and evaluation for the student. The aim was to gather the opinions of the research sample, analyze them, and reveal the relationship between the first axis (using e-learning strategy in improving the learning of mathematics) and the second axis with all its domains that address the internal and external variables aforementioned in the research questions. Mathematics faculty member questionnaire included (30) paragraphs, distributed (5) items for each of the learning, evaluation, obstacles, the need for training for a faculty member and for the student, based on the results of the students' questionnaire, so the answers strengthened the interpretation of some of the results made by the students

\subsection{Total Community of Research and Its Characterization}

1) Students who study mathematics courses and are registered in the first semester of the academic year $1442 \mathrm{AH}$ in the College of Arts and Sciences and the College of Engineering in Wadi Al-Dawasir and their number is (223) male and female students.

2) University professors who teach mathematics at the College of Arts and Sciences and the College of Engineering in Wadi Al-Dawasir at Prince Sattam University, their number is (34) faculty members.

\subsection{Research Sample}

The research was limited to a random sample of (74) male students and (36) female students, which is the number of correct responses to the questionnaire, representing $51.64 \%$ of the registered students in the first semester of the academic year $2021 \mathrm{AD}$, at Prince Sattam bin Abdul-Aziz University in Wadi Al-Dawasir, and all members of the total community mathematics faculty who are (25) faculty members in the College of Arts, Sciences, and (9) faculty members in the College of Engineering.

Description of the research sample of university students:

Table 1. shows the distribution of the sample of university students according to academic achievement

\begin{tabular}{ccc}
\hline College & \multicolumn{2}{c}{ Academic Achievement } \\
& Less than 3 & 3 and Up \\
\hline Arts and Science & 25 & 67 \\
Engineering & - & 18 \\
Total & 25 & 85 \\
Ratio & 22.73 & 77.27
\end{tabular}

It is clear from Table 1. that most of the sample members account for $77.27 \%$ of those with academic achievement (3 or more).

Table 2. shows the distribution of university students according to Gender

\begin{tabular}{ccccc}
\hline Specialization & Male & Sex & Female & Ratio \\
\hline Arts and Science & 56 & 36 & 83.63 \\
Engineering & 18 & - & 16.73 \\
Total & 74 & 36 & $\% 100$ \\
\hline
\end{tabular}

10.5 Statistical Tests and Analyzes

\subsubsection{Statistical Standard}

The five-point Likart scale was adopted and to correct the search tool each element of its ratings (Strongly Agree, Agree, Neutral, Disagree, Strongly Disagree) was given a numeric representation of $(5,4,3,2,1)$ respectively, after collecting data with the search tool, the researcher analyzed it using: (frequencies and percentages, arithmetic mean and standard deviation, ( $\chi^{2}$ test), T-test, trace size for square $\varnothing$ ). 


\subsubsection{Internal Consistency of the Paragraphs of the Questionnaire}

The correlation coefficients of the score of each paragraph with the score of the field and the fields with the total score of the tool were calculated, using Pearson's correlation coefficient, it was (0.930), which indicates the existence of internal consistency between the paragraphs and the field and between the domains and the tool.

\subsubsection{Stability}

To find out the stability of the tool, the questionnaire was distributed to (5) faculty members and (20) students, and the questionnaire was redistributed to them again after ten days had passed to answer it, then the correlation coefficient was calculated between their answers both times, using Cooper's equation, the correlation coefficient was It is (0.835), which indicates the availability of the condition of stability in the resolution.

Mathematics faculty survey: The researcher designed the mathematics faculty members 'questionnaire based on the results of the students' questionnaire, so the answers strengthened the interpretation of some of the results made by the students. As for the questionnaire of mathematics faculty members, after collecting the data, it was divided into topics, under which there are subsections. Emphasis was placed on relevant data, which explain some of the findings and add depth to the study.

\section{Research Findings and Discussions}

\subsection{Findings}

The text of the first question: What is the role of using the e-learning strategy in achieving improvement of the learning of mathematics at the undergraduate level from the students' point of view?

To know the use of e-learning strategies to improve the education process of undergraduate students, the $(\chi 2)$ test was used to analyze the results of the questionnaire, and to find a practical indication of the resulting individual values or differences, the effect size was used. (Ø). The results of the questionnaire in the first axis showed that the use of e-learning to improve the mathematics education process (3.41).

It is clear from table 3 . The existence of statistically significant differences at the level of significance $(0.05)$ and at the degree of freedom (4), as the value of $\left(\chi^{2}\right)$ read under these conditions is (9.448) smaller than the value of $\left(\chi^{2}\right)$ calculated.

Table 3. Illustrates using e-learning strategies in improving education mathematics

\begin{tabular}{ccccccccccc}
\hline No & $\begin{array}{c}\text { Strongly } \\
\text { Agree }\end{array}$ & Agree & Neutral & Disagree & $\begin{array}{c}\text { Strongly } \\
\text { Disagree }\end{array}$ & $\begin{array}{c}\text { Calculat } \\
\text { ed }\left(\chi^{2}\right) \\
\text { Value }\end{array}$ & $\begin{array}{c}\text { Degree } \\
\text { of } \\
\text { Freedom }\end{array}$ & Function & Ǿ Square & Impact \\
\hline 1 & 21 & 24 & 28 & 19 & 18 & 3.03 & 4 & $\begin{array}{c}\text { Not } \\
\text { Function }\end{array}$ \\
2 & 21 & 24 & 30 & 10 & 15 & 11.92 & 4 & Function & 0.33 & Average \\
3 & 25 & 40 & 23 & 5 & 17 & 29.91 & 4 & Function & 0.52 & Large \\
4 & 31 & 26 & 13 & 13 & 27 & 12.91 & 4 & Function & 0.34 & Average \\
5 & 44 & 21 & 31 & 3 & 11 & 47.64 & 4 & Function & 0.66 & Large \\
6 & 39 & 33 & 14 & 4 & 20 & 36.45 & 4 & Function & 0.58 & Large \\
7 & 49 & 33 & 6 & 12 & 20 & 49.55 & 4 & Function & 0.67 & Large \\
8 & 38 & 20 & 20 & 5 & 27 & 26.28 & 4 & Function & 0.49 & Average \\
9 & 47 & 20 & 15 & 12 & 16 & 37.01 & 4 & Function & 0.58 & Large \\
10 & 23 & 30 & 26 & 12 & 19 & 8.65 & 4 & Not & & Function \\
\end{tabular}

The results of the questionnaire in the first axis also showed that the use of e-learning to achieve improvement in the mathematics learning process with a score of (3.15).

It can be seen from table 4: The existence of statistically significant differences at the level of significance $(0.05)$ and at the degree of freedom (4), as the value of $\left(\chi^{2}\right)$ read under these conditions is (9.448) smaller than the value of $\left(\chi^{2}\right)$ calculated. 
Table 4. Illustrates using e-learning strategies in improving learning mathematics

\begin{tabular}{ccccccccccc}
\hline \multicolumn{1}{c}{ No } & $\begin{array}{c}\text { Strongly } \\
\text { Agree }\end{array}$ & Agree & Neutral & Disagree & $\begin{array}{c}\text { Strongly } \\
\text { Disagree }\end{array}$ & $\begin{array}{c}\text { Calculated } \\
\left(\chi^{2}\right) \text { Value }\end{array}$ & $\begin{array}{c}\text { Degree of } \\
\text { Freedom }\end{array}$ & Function & $\begin{array}{c}\text { Ǿ } \\
\text { Square }\end{array}$ & Impact \\
\hline 1 & 32 & 29 & 19 & 9 & 21 & 15.72 & 4 & Function & 0.40 & Average \\
2 & 14 & 34 & 27 & 5 & 30 & 22.65 & 4 & Function & 0.49 & Average \\
3 & 39 & 20 & 14 & 14 & 23 & 19.19 & 4 & Function & 0.48 & Average \\
4 & 34 & 14 & 29 & 6 & 27 & 14.47 & 4 & Function & 0.36 & Average \\
5 & 26 & 30 & 16 & 11 & 27 & 11.92 & 4 & Function & 0.33 & Average \\
6 & 25 & 32 & 20 & 6 & 27 & 17.92 & 4 & Function & 0.40 & Average \\
7 & 23 & 27 & 20 & 8 & 32 & 14.83 & 4 & Function & 0.37 & Average \\
8 & 42 & 14 & 19 & 12 & 23 & 26.1 & 4 & Function & 0.49 & Average \\
9 & 36 & 16 & 23 & 15 & 20 & 5.01 & 4 & Not & 0.00 & Function \\
10 & 28 & 41 & 19 & 5 & 70 & 32.74 & 4 & Function & 0.55 & Large \\
\hline
\end{tabular}

The results of the questionnaire in the first axis showed that the use of e-learning to achieve improvement in the mathematics evaluation process with a score of (3.7).

It can be seen from table 5: The existence of statistically significant differences at the level of significance (0.05) and at the degree of freedom (4), as the value of $\left(\chi^{2}\right)$ read under these conditions is (9.448) smaller than the value of $\left(\chi^{2}\right)$ calculated for all the paragraphs.

Table 5. Illustrates using e-learning strategies in improving evaluating mathematics

\begin{tabular}{|c|c|c|c|c|c|c|c|c|c|c|}
\hline \multirow{2}{*}{ No } & \multicolumn{5}{|c|}{ Frequency } & \multirow[t]{2}{*}{$\begin{array}{l}\text { Calculated } \\
\left(\chi^{2}\right) \text { Value }\end{array}$} & \multirow[t]{2}{*}{$\begin{array}{l}\text { Degree of } \\
\text { Freedom }\end{array}$} & \multirow[t]{2}{*}{ Function } & \multirow[t]{2}{*}{$\begin{array}{c}\emptyset \\
\text { Square }\end{array}$} & \multirow[t]{2}{*}{ Impact } \\
\hline & $\begin{array}{c}\text { Strongly } \\
\text { Agree }\end{array}$ & Agree & Neutral & Disagree & $\begin{array}{l}\text { Strongly } \\
\text { Disagree }\end{array}$ & & & & & \\
\hline 1 & 37 & 26 & 20 & 8 & 19 & 12.46 & 4 & Function & 0.37 & Average \\
\hline 2 & 23 & 40 & 15 & 16 & 16 & 20.29 & 4 & Function & 0.43 & Average \\
\hline 3 & 28 & 43 & 20 & 5 & 17 & 36.82 & 4 & Function & 0.58 & Large \\
\hline 4 & 20 & 54 & 14 & 12 & 17 & 63.92 & 4 & Function & 0.76 & Large \\
\hline 5 & 32 & 35 & 14 & 12 & 17 & 20.83 & 4 & Function & 0.44 & Average \\
\hline 6 & 30 & 38 & 20 & 8 & 14 & 26.55 & 4 & Function & 0.49 & Average \\
\hline 7 & 43 & 22 & 15 & 11 & 19 & 28.19 & 4 & Function & 0.51 & Large \\
\hline 8 & 34 & 26 & 10 & 18 & 22 & 12.06 & 4 & Function & 0.33 & Average \\
\hline 9 & 28 & 39 & 20 & 4 & 19 & 30.1 & 4 & Function & 0.52 & Large \\
\hline 10 & 25 & 11 & 11 & 6 & 21 & 46.01 & 4 & Function & 0.65 & Average \\
\hline
\end{tabular}

Text of the second question: What are the obstacles facing the use of the e-learning strategy in improving the teaching, learning and evaluation of mathematics at the university level?

The results of the university student questionnaire on the education axis also showed that the phrases (teaching mathematical concepts more easily, developing the relationship between the faculty member and the university student) got the lowest percentage.

The results of the student's questionnaire on the learning axis revealed that the phrases (increasing effectiveness in learning mathematical subjects, developing skills in solving mathematical problems, using various means to activate mathematical proof) got the lowest percentage. 
The results of the student's questionnaire in the evaluation axis indicated that the two statements (providing information about the student's learning level in mathematics, achieving a fair assessment of the student's effort) got the lowest percentage in the axis.

The text of the third question: Are there statistically significant differences between the overall averages of students' responses about using the e-learning strategy to improve mathematics learning due to the GPA variable (less than 3, 3 or more)?

To find out the effect of the GPA (less than 3, 3 or more) on the overall averages of students' responses about the use of e-learning strategies in improving the learning of mathematics, the (T- test) was used, from table $6 . t=(1.366)$ it was not statistically significant at (0.05) level, which indicates that the GPA does not affect the overall averages of students' responses about the use of e-learning strategies in improving the learning of mathematics.

Table 6. Illustrates the relationship between the GPA of the university student and the use of E-learning strategies to improve the learning of mathematics

\begin{tabular}{cccccccc}
\hline \multicolumn{7}{c}{ Group Statistics } \\
\hline $\begin{array}{c}\text { Cumulativ } \\
\text { e average } \\
\text { Less than }\end{array}$ & $\mathrm{N}$ & Mean & Std. Deviation & $\mathrm{T}$ & Df & Sig. (2-tailed) \\
Average & 3 & 25 & 3.444 & .9751 & 1.366 & 108 & 0175 \\
& 3 or more & 85 & 3.091 & 1.1790 & & &
\end{tabular}

The text of the fourth question: Are there statistically significant differences between the overall averages of students' responses regarding the use of the e-learning strategy in improving learning of mathematics due to the gender variable (male, female)?

To find out the effect of gender (male, female) on the overall averages of students' responses to the use of e-learning strategies in improving the learning of mathematics, the (T- test) was used. from table $7 . t=(0.186)$ It was not statistically significant at (0.05) level, which indicates that gender did not affect the overall averages of students' responses about the use of e-learning strategies in improving learning of mathematics .

Table 7. Illustrates the relationship between the gender of the university student and the use of E-learning strategies to improve the learning of mathematics

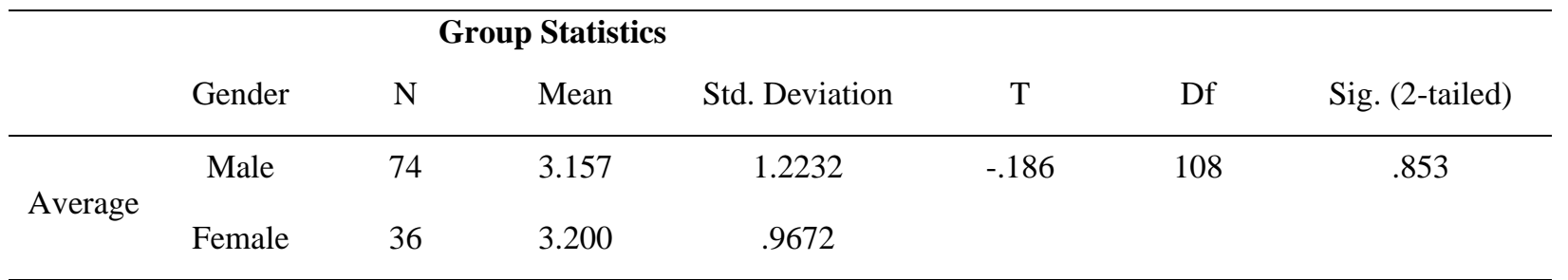

The text of the fifth question: What is the need for training to take advantage of the characteristics provided by the use of e-learning strategies to improve the teaching, learning and evaluation of mathematics?

The results of the survey of mathematics faculty members confirmed the need to hold professional and educational training courses for mathematics faculty members to take advantage of the characteristics provided by the use of e-learning strategies in teaching, learning and evaluating mathematics, where $(52.9 \%)$ mentioned better teaching mathematical concepts, and (44.1\%) using different methods of evaluation, evaluating the student on an ongoing basis, working on serious stimulation of students 'thinking, and involving the student in discovering mathematical information. They also emphasized the need to hold training courses for students to take advantage of the characteristics provided by e-learning in teaching and learning mathematics, mentioning a percentage (61.8\%) to absorb mathematical courses more easily, (58.8\%) developing skills in solving mathematical problems, and a rate of $(55.9 \%)$ an increase in its effectiveness in learning mathematical topics.

\subsection{Discussion}

The results of the university student's questionnaire on the education pillar overall, it was found that most undergraduate students at Prince Sattam bin Abdulaziz University in Wadi Al-Dawasir believe that using e-learning strategies improves the process of mathematics education by a rate ranging between $0.33 \%$ and $0.67 \%$, the two phrases (teaching mathematical concepts more easily, developing the relationship between a faculty member and the university 
student) got the lowest percentage, and the results of the mathematics faculty survey confirmed that using E-learning strategies in teaching mathematics help a member of the mathematics faculty in performing his educational tasks easily and dynamically, as he mentioned (50\%) that would lead to the possibility of measuring mathematics learning objectives, and (35.3\%) mentioned working to correct the student's learning path, and he mentioned The percentage $(23.5 \%)$ of the increase in the vitality and activity of the faculty member. This is consistent with the study of Al-Zahrani (2005), which confirmed the positive trends of secondary school teachers in using the Internet in teaching mathematics to a high degree. This research added his undergraduate interest in the direction of teachers towards using e-learning strategies in teaching mathematics.

The results of the student questionnaire in the learning axis overall, it was found that most of the undergraduate students at Prince Sattam bin Abdulaziz University in Wadi Al-Dawasir believe that using e-learning strategies improves the mathematics learning process by a rate ranging between $0.33 \%$ and $0.55 \%$, and revealed that the phrases (increasing effectiveness in learning mathematical subjects, developing mathematical problem-solving skills, using various means to activate mathematical proof) got the lowest percentage, and the mathematics faculty confirmed that the use of e-learning strategies in teaching mathematics helps the student The university received the educational process with a desire and vitality, so the percentage (64.6\%) stated that it works to keep the information for a longer time, and he mentioned (41.2\%) that makes the lesson enjoyable for him. This is consistent with the study of Al-Maghribi (2000), which confirmed the existence of statistically significant differences in favor of the experimental group in the collection process. Overall, it was found that most undergraduate students at Prince Sattam bin Abdulaziz University in Wadi Al-Dawasir see that the use of e-learning strategies improves the mathematics evaluation process by a rate ranging between $0.33 \%$ and $0.76 \%$. This is consistent with the study of Amanda, A., Andrea, M., Mike, M. (2006). self-evaluation and interviews can be used. This research added the student's lack of motivation towards using e-learning strategies in the learning process.

The results of the student's questionnaire in the evaluation axis indicated that the two statements (providing information about the student's learning level in mathematics, achieving a fair assessment of student effort) got the lowest percentage in the axis, and the results of the mathematics faculty survey confirmed that using e-learning strategies appoint a mathematics faculty member in Evaluating the university student with credibility and fairness, where a percentage $(47.1 \%)$ stated that it works on using different types of tests, a percentage (52.9\%) mentioned training the student in accuracy in studying, and a percentage (35.3\%) mentioned the provision of specific mechanisms in calculating test scores and assignments, It enables the student to self-evaluate his academic achievement, respectively. This research added the lack of credibility of the assessment as the student can seek the help of others.

Through the arithmetic averages, we find that students have confirmed a greater degree of e-learning in the two axes of education and evaluation compared to the learning axis. The two arithmetic averages for each came respectively (3.41, 3.7), while for the learning axis the arithmetic mean was (3.15), and the reason may be attributed to the traditional style of teaching mathematics that makes electronic application more difficult in the learning axis.

Results of the obstacles facing the use of the e-learning strategy in improving the teaching could be explained by the fact that mathematics is an abstract subject and needs a faculty member to present it in a simple and tangible way. The student interacts with it, in addition to the weak relationship in the first place, especially humanity, between a faculty member and the student in e-learning in general, and the results of the obstacles facing the use of the e-learning strategy in improving the learning could be explained by the fact that e-learning requires the student to practice the role of an explorer, which requires with him previous experience in mathematical topics and a certain desire to reach specific results, in addition to the problems of availability and strength of the network that often reduce the motivation of the student and his desire to continue learning.

The survey of mathematics faculty members at a rate of (38.8\%) indicated a weak desire the student in e-learning. A percentage $(64.6 \%)$ stated that it works to retain the information for a longer time, and a percentage $(41.2 \%)$ makes the lesson interesting for him. This is consistent with the study of Al-Hadi (2005), which confirmed the existence of statistically significant differences in achievement in favor of the male experimental group. This research added that there were no differences in the use of e-learning strategies due to the gender variable.

Results of the obstacles facing the use of the e-learning strategy in improving the evaluation could be explained by the fact that solving the assignments does not indicate the student's actual level, where the student can use others. The results of the questionnaire confirmed that the obstacles facing the application of the e-learning strategy in the teaching and learning process and evaluation of mathematics at the university level is represented by the weakness of the Internet in many cases (94.7\%), the lack of availability of modern devices among students $(68.4 \%)$, and the weak 
desire of the student for e-learning (38.8\%). This is consistent with the study of Abuhmaid (2020), which show that students in the classroom have stronger views of project-based learning than online learning students.

The reason of GPA does not affect the overall averages of students' responses about the use of e-learning strategies in improving the learning of mathematics, may be that university students are more aware of the importance of using e-learning to improve opportunities Teaching, learning and evaluation Where once the infrastructure is available, the result of improving teaching, learning and evaluation will be clear. This is consistent with Al-Tamimi (2007) study, which indicated the availability of equipment, software, and standards for teaching mathematics to mathematics teachers.

The reason of gender did not affect the overall averages of students' responses about the use of e-learning strategies in improving mathematics learning, may be that all university students (males and females) show a high degree of interest. With technology and dealing with it, they are certain of its importance in improving the teaching process. This is consistent with the study of Al-Maghribi (2000), which confirmed that there are no statistically significant differences for sex. This research added that there were no differences in the use of e-learning strategies due to the achievement.

The results of the survey of mathematics faculty members confirmed the need to hold professional and educational training courses for mathematics faculty members and students to take advantage of the characteristics provided by the use of e-learning strategies in teaching, learning and evaluating mathematics, this can be explained by the belief of mathematics faculty members and students that the application of e-learning leads to positive results in the field of learning and teaching mathematics at the university level. This is consistent with Al-Harbi study (2007), where it indicated the necessity of providing the infrastructure standards (educational infrastructure, mathematics curriculum and mathematics teacher), also consistent with Abdel-Hafiz (2020), which indicated an increasing interest in training mathematics faculty members on new developments in the field of educational technology. This research added motivating teachers interested in using e-learning strategies.

\section{Conclusions}

In light of the rapid trends in the use of e-learning strategies in most countries, especially in light of the Corona (Covid-19) pandemic, this research constitutes an important addition, as it showed that the use of e-learning strategies in improvement of the teaching, learning and evaluation process from the students 'point of view in an aggregate form (3.42) which is higher than the theoretical average which is (3). There are also obstacles facing the use of e-learning strategies in learning, the most important of which is the student's lack of motivation to learn through it, the weakness of the electronic network and the lack of credibility of evaluation through it. Also, academic achievement and student gender have no effect in using e-learning strategies to improve mathematics learning. The need for continuous training of faculty members and students on all developments in the field of using e-learning strategies to make the most of its features and capabilities in improving mathematics teaching.

\section{Suggestions and Recommendations}

- Continuity of training faculty members on new developments in the field of educational technology.

- Employing the characteristics of e-learning in linking the theoretical aspects of mathematics with its practical applications.

- Encouraging university students to make use of the available smart communication means and training to use them periodically.

- Encouraging action research in the field of benefiting from the use e-learning strategies at the various educational stages.

- Overcoming obstacles facing the application of e-learning strategies, especially with regard to the Internet.

- Motivating teachers interested in using e-learning strategies.

\section{References}

Abdel Aziz, H. (2008). E-learning, philosophy - principles - tools - applications. Amman, home of thought.

Abdel-Hafiz, N. (2020). The Role of E-Learning in Improving Mathematics Education at the University Level, Ge Lai Zanst Magazine, 5(1). https://doi.org/10.25212/lfu.qzj.5.1.25

Abuhmaid, A. M. (2020). The efficiency of online learning environment for implementing project-based learning: Students' perceptions. International Journal of Higher Education, 9(5), 76-83. https://doi.org/10.5430/ijhe.v9n5p76 
ackstein, S., Coleman, E., \& Ndobe, T. V. (2019). Lecturers' Perceptions of Learning Management Systems Within a Previously Disadvantaged University, 1-28. https://doi.org/10.4018/978-1-5225-7473-6.ch001

Al- Musharraf, Ab. (2004). E-learning is not a substitute for the teacher, but rather enhances his role. Computer Oasis Magazine, No. 25, Ministry of Education. 26-27.

Al-Arifi, Y. Ab. (2003). E-learning is a promising technology and a pioneering method. A working paper submitted for the e-learning symposium during the period 12-23 April, King Faisal Schools, Riyadh. http://www.jeddahedu.gov.sa/NEWS/papers/p1.doc

Al-Dayel, S., \& Salama, Ab. (2004). Education Technology Series, Introduction to Educational Technology. Al-Khuraiji Publishing House, Riyadh.

Al-Hadi, M. M. (2005). E-learning via the Internet. Egyptian Lebanese House, Cairo.

Al-Halfawi, W. (2011). E-learning innovative applications. Arab Thought House, Cairo.

Al-Hamili, Y. J. (2005). The Reality of Using Computers in the Governmental Sector in the Kingdom of Saudi Arabia, Obstacles and Solutions, Institute of Public Administration, Riyadh.

Al-Harbi, M. S. (2007). The demands of using e-learning to teach mathematics at the secondary level from the practitioners' and professionals point of view. (PhD thesis), Umm Al-Qura University, Kingdom of Saudi Arabia.

Al-Maghribi, A. Y. (2000). The effect of using programmed education on achieving mathematics at the basic stage. (Master Thesis), University of Khartoum, supplementary research.

Al-Mubarak, A. A. (2005). The effect of teaching using virtual classrooms via the global network "the Internet" on the achievement of students of the College of Education in Teaching and Communication Technologies at King Saud University, (Master Thesis), King Saud University, Riyadh. http//:www.mohysin.com

Al-Musa, A., \& Al-Mubarak, Ab. (2005). E-learning, foundations and applications. Data Network Corporation, Al-Obeikan Library, Riyadh, Kingdom of Saudi Arabia.

Al-Tamimi, A. (2007). The reality of using e-learning in teaching mathematics at the secondary level in some countries, in light of NCTM, (PhD thesis), Umm Al-Qura University, Makkah Al-Mukarramah.

Al-Todri, A. M. (2001). The electronic school and modern roles for the teacher. Al-Rushd Library, Riyadh.

Álvarez, D., Moreno, P., Orduna, V., Pascual \& F. J. San Vicente. (2015). Maths: from distance to e-learning, International Journal of Interactive Multimedia and Artificial Intelligence, 3(4), 9. https://doi.org/10.9781/ijimai.2015.341

Al-Zahrani, Ab. O. (2005). The reality of using computers and the Internet in teaching mathematics at the secondary level from the point of view of teachers and educational supervisors. (Master Thesis), Umm Al-Qura University, Makah al- Mukarramah.

Amanda, A., Andrea, M., \& Mike, M. (2006). E-Learning Evaluation, In E-learning Concepts and Techniques, Institute for Interactive - Technologies, Bloommsburg University of Pennsylvania, USA

Aqeelan, I. M. (2002). Mathematics curricula and methods of teaching it. Second Edition, Dar Al Masirah, Amman.

Azmi, N. (2006). E-learning technology. Cairo, the Arab Thought House.

Comerchero, M. (2005). E-learning concepts and techniques: what is e-learning, institute for interactive technologies, bloomsbrug university of pennsyvania, USA

DLal, Z., \& Al-Jundi, A. (2005). Electronic Communication and Education Technology, 3rd i. Obeikan Library, Riyadh.

Epignosis, L. L. C. (2014). E-Learning Concepts, Trends, Applications. E-Book. V1-1. www.talenlms.com

Fathallah, M. A. (2004). Basics of Using Educational Technology Means. Riyadh, Al-Sumaiy House.

Harvey, L. (2004). Analytic Quality Glossary. Quality Research International www.qualityresearchinternational.com/glossary/effectiveness.htm

Hubackova, S. (2015). History and Pespectives of E- Learning, Proedia. Social and Behavioural Sciences, 191, 1189-1190. https://doi.org/10.1016/j.sbspro.2015.04.594

Karawani, M. N. (2012). Attitudes of Mathematics and Computer Students at Al-Quds Open University, C-Lift 
Educational Zone - Towards the Use of E-Learning in Learning Mathematics, The Palestinian Journal of Open Education and E-learning, 3(6). http://journals.qou.edu/index.php/jropenres/article/view/325

Makgato, M. (2014). The challenges of teaching and learning technology subject at schools in South Africa: A case of INSET teachers in Mpumalanga Province. Procedia-Social and Behavioural Sciences, 116, 3688-3692. https://doi.org/10.1016/j.sbspro.2014.01.824

Mansour, A. I. (2015). Educational Technology. (First Edition), Jordan, Al-Janadriyah Publishing and Distribution.

Oyedemi, T. D. (2012). Digital inequalities and implications for social inequalities: A study of Internet penetration amongst university students in South Africa. Telematics and Informatics, 29(3), 302-313. https://doi.org/10.1016/j.tele.2011.12.001

Padayachee, I. (2017). Educator perceptions of virtual learning system quality characteristics. South African Computer Journal, 29(3), 95-126. https://doi.org/10.18489/sacj.v29i3.418

Protheroe, N., \& Clarke, S. (2008). Learning Strategies as a Key to Student Success. Principal, 88(2), 33-37.

Rubaai, N., \& Hashim, H. (2019). Polytechnic ESL lecturers' acceptance of using Massive Open Online Course (MOOC) for teaching English as a Second Language (ESL). International Journal of Innovative Technology and Exploring Engineering, 8(9),114-121.https://doi.org/10.35940/ijitee.I7530.078919

Salama, A. Ab. (2007). What is the opinion and strength of knowledge? an article in the Forum for Educational Planning and Development. http://www.ta ${ }^{9}$ weer.com/vb/archive/index.php/t- 1 r $4 . h t m$.

Viswanath, V., Morris, M. G., Davis, G. B., \& Davis, F. D. (2003). User acceptance of information technology: Toward a unified view. MIS quarterly, 425-478. https://doi.org/10.2307/30036540

Zaitoun, H. H. (2005). A new vision in learning, e-learning, the concept, issues, implementation, evaluation. Sound House for Education, Riyadh.

\section{Copyrights}

Copyright for this article is retained by the author(s), with first publication rights granted to the journal.

This is an open-access article distributed under the terms and conditions of the Creative Commons Attribution license (http://creativecommons.org/licenses/by/4.0/). 